\title{
Principles and supporting agreement for the transparent task model of electricity price issuing and transformer district tests
}

\author{
Wang Gang ${ }^{1, a}$, Liu Xiaohua ${ }^{2, b}$, Dai Xiaofei ${ }^{2, c}$, Zhang Lequn ${ }^{3, d}$ \\ ${ }^{1}$ Electric Power Research Institute of State Grid XinJiang Electric Power Corporate, Urumchi, \\ 830000, China \\ ${ }^{2}$ State Grid XinJiang Electric Power Corporate, Urumchi, 830000, China \\ ${ }^{3}$ Qingdao Topscomm Communication Co.,Ltd, 266000, Qingdao, China \\ a wg619@126.com, ${ }^{\text {b } 1173308892 @ q q . c o m, ~}{ }^{\text {c } 390421162 @ q q . c o m, ~}$ \\ d zhanglequn@toscomm.com
}

Key words: Transparent task, meter reading model, expansion agreement, transformer district test

\begin{abstract}
This paper introduces the principles of electricity price-issuing model under a transparent task and a supporting expansion agreement. Moreover, it describes the technical features and advantages of the electricity price-issuing model by comparing it with traditional transparent transmission terminals. Examples of the test results from the transformer district indicate an obvious issuing effect of electricity price under the transparent task model.
\end{abstract}

\section{Introduction}

The insufficient power supply in many provinces and regions cannot be improved in the short term. Therefore, orderly and proper power consumption management mostly depends on the improvement of the collection system. The tiered pricing policy of electricity has been accepted by related organizations and markets, and its use has further increased the multi-functional demand for a collection system. The local intelligent electric meter [3] (hereinafter referred to as meter), which promotes the intelligent construction of a collection system, applies prepayment and consumption modes and has solved the problems of having a large workload of manual meter reading and difficult collection of bills. Therefore, its application range has been increasingly wide. The access amount for meters in most cities has exceeded $90 \%$, which has resulted in the difficulty of electricity price issuing. The working mode for electricity price issuing in the current power information collection system is the transparent terminal transmission [4], i.e., the primary station sends the electricity bill through the transparent terminal transmission. Based on the actual data from the site, the success rate of this solution is low, the period is long, and about $30 \%$ or even more failed sending tasks can occur. Thus, a site manual adjustment is necessary, and more labor, materials, and time are consumed.

\section{Transparent task model}

Electric power companies have been devoted to conducting research and development on more advanced electricity price-issuing models [5]. The traditional terminal transmission-based electric price issuing process is the communication between the primary station and the intelligent electric meter, similar to remote meter reading, both of which have the same channel. As a whole, the success rate for remote meter reading in the transformer district is about more than 95\% without obvious faults, and the rate for transformer district s in most regions can exceed $98 \%$. For example, as shown in Table 1 (see Table 1 for transformer district examples; region names are presented by initials in Pinyin), it is obviously higher than the success rate of electricity price issuing under the terminal transparent transmission model. Therefore, the essential differences between the terminal transparent transmission model applied for traditional electricity price issuing and the remote meter reading model should be determined [6]. The differences are analyzed as follows: 


\begin{tabular}{|c|c|c|c|c|c|}
\hline Power supply organization & \begin{tabular}{|c|} 
Installed \\
electric \\
meter \\
reading
\end{tabular} & $\begin{array}{c}\text { Required } \\
\text { electric } \\
\text { meter } \\
\text { reading }\end{array}$ & $\begin{array}{c}\text { Successful } \\
\text { reading }\end{array}$ & $\begin{array}{c}\text { Failed } \\
\text { reading }\end{array}$ & $\begin{array}{c}\text { Successful } \\
\text { reading } \\
\text { rate }\end{array}$ \\
\hline CF Power supply bureau & 268479 & 267835 & 266437 & 1398 & $99.48 \%$ \\
\hline PZ Agricultural electricity bureau & 43062 & 43060 & 42857 & 203 & 99.53\% \\
\hline YBS Agricultural electricity bureau & 11082 & 9331 & 9284 & 47 & $99.50 \%$ \\
\hline HSQ Agricultural electricity bureau & 483 & 483 & 481 & 2 & $99.59 \%$ \\
\hline $\begin{array}{c}\text { KSKTQ Agricultural electricity } \\
\text { bureau }\end{array}$ & 54105 & 45030 & 44673 & 357 & $99.21 \%$ \\
\hline
\end{tabular}

Table. 1 Statistics of actual successful meter reading rates in some regions

\subsection{Electricity price issuing under the terminal transparent transmission model}

In the electricity price issuing under the transparent terminal transmission model, the concentrator, as a transparent retransmission channel only, requires establishing a communication link to the eletric energy meter in real time during the electricity price issuing and has a high requirement for real and reliable communication. The primary station and concentrator submit the identification results and sets the result report overtime. If one of the four elements does not work properly, the task of electricity price issuing fails. Therefore, they are all set in a real-time task. The success rate for communication is obtained by multiplying the the single rate $P_{i}$ (i.e., $0<P_{i}<1$, $P_{i}=0$ means that it is the device's fault, and $P_{i}=1$ means no long-term $100 \%$ success rate; both are not inclusive) (see formula (1)). In case of other devices such as the concentrator, the probability multiplier $n$ increases, and the total communication success rate $P$ decreases.

$$
P=\prod_{i=1}^{n} P_{i}, n \geq 2,0<P_{i}<1 \text {. }
$$

Assume that $n=3$. Even if $P_{i}=90 \%$ and $i=1,2,3$, the success rate for a single task is only $P=0.9^{3}=72.9 \%$. This finding results in the unavailable implementation of a task with synchronous demands in the current meter reading structure. This outcome is one of most important technical reasons why only about $70 \%$ of electricity price issuing is under the transparent terminal transmission mode.

\subsection{Electricity price issuing under the transparent task mode}

When the electric bill is sent by the meter reading method, the primary station sets the commands for all electric prices in the electric meter and sends them to the concentrator. The task queue for electricity price issuing is established in the concentrator, which can continuously execute the commands for electricity price issuing within the meter reading time range. The process of the electricity price parameter issuing is identical to that for reading daily frozen data from the current concentrator.

The method of executing electricity price issuing by meter reading plays the role of a concentrator, which can optimize the execution of the commands for electricity price issuing based on the internal reading routes. It can also flexibly control and handle abnormal conditions, such as communication overtime. Only the process of identification has a term of validity in the entire transparent task process. It avoids the unlimited waiting of tasks and problems caused by different manufacturers having different times for overtime. Moreover, it unifies the overtime threshold for the entire system. The sending task to different electric energy meters applies a priority strategy that does not affect the daily collection. The task of electricity price issuing can be implemented for many times, so that the electricity price can be sent to all electric energy meters that successfully meets the identification process. According to tests from the transformer district, the success rate for electricity price issuing has increased, reaching the level of success rate for meter reading. The results of the tests from the transformer district are described in section 4 . 


\section{Supporting the transparent task mode Q/GDW1376.1-2013[7] design for the expansion agreement}

Through the coordination of the power supply company and support from the device manufacturer, related agreement contents have been expanded for electricity price issuing under the transparent task mode to support businesses. Currently, the expansion agreement mainly expands the AFN to task setting $10 \mathrm{H}$, task status $0 \mathrm{CH}$, and task report $0 \mathrm{EH}$. The agreement will be continuously improved in the experiment tasks. A definition example of the expansion agreement are introduced below.

F305-307 is used for task setting to clear, set, and query the utilization of the transparent task, and for uplinking and downlinking the message to meet the format requirements for the data-forwarding commands in Q/GDW 1376.1-2013. Table 2 presents the unit format for the F306 downlink data.

\begin{tabular}{|c|c|c|c|}
\hline Data contents & $\begin{array}{c}\text { Data } \\
\text { format }\end{array}$ & Unit & $\begin{array}{c}\text { Numb } \\
\text { er of } \\
\text { bytes }\end{array}$ \\
\hline Task number & BIN & & 2 \\
\hline Task priority & BIN & & 1 \\
\hline Task marks & BIN & & 1 \\
\hline Effective duration of terminal tasks & BIN & Minute & 1 \\
\hline Total number of task messages & BIN & & 1 \\
\hline $\begin{array}{c}\text { Number of messages for the current } \\
\text { frame }\end{array}$ & BIN & & 1 \\
\hline Message 1 number & BIN & & 1 \\
\hline Message 1 length (L1) & BIN & & 1 \\
\hline Message 1 contents & BIN & & L1 \\
\hline$\ldots . . .$. & & & $\ldots \ldots$ \\
\hline Message n number & BIN & & 1 \\
\hline Message $n$ length (Ln) & BIN & & 1 \\
\hline Message n contents & BIN & & Ln \\
\hline
\end{tabular}

Table. 2 Setting of the data unit format in the transparent task

The message format of the uplink and downlink message for the task status satisfies the requirements of the request class 1 in Q/GDW 1376.1-2013. The F305 is applied for the query and reply transparent task status, and the F306 is used for the query and reply transparent task results. Table 3 presents the unit format of the F306 downlink data.

\begin{tabular}{|c|c|c|c|}
\hline Data contents & $\begin{array}{c}\text { Data } \\
\text { format }\end{array}$ & Unit & $\begin{array}{c}\text { Number } \\
\text { of bytes }\end{array}$ \\
\hline $\begin{array}{c}\text { Query amount for the } \\
\text { current frame }\end{array}$ & BIN & & 1 \\
\hline First message number & BIN & & 1 \\
\hline$\ldots \ldots$ & BIN & & \\
\hline $\mathrm{m}^{\text {th }}$ message number & BIN & & 1 \\
\hline
\end{tabular}

Table. 3 Query results of the transparent task for the data unit format

The agreement also indicates that all transparent tasks are within the clear terminals of the primary station before they are sent. After accepting the transparent task, the terminal restarts the 
local communication module. When transparent task is executed and the terminal accepts the subsequent transparent task, the local communication module cannot be restarted. In the future, guidance from the State Grid Measurement Center will be required for continuous improvement.

\section{Test verification of the transformer district for electricity price issuing under the transparent task mode}

The test results for the electricity price issuing under the transparent task mode in the first 12 transformer districts are provided as follows. The total number of the local expense control meter is considered the base number for the success rate statistics because of the small number of old meters that do not support electricity price issuing in the transformer district. Table 4 presents the results. The name of the transformer district is described by initials in Pinyin.

\begin{tabular}{|l|l|l|l|l|}
\hline Name of collection point & $\begin{array}{c}\text { Total } \\
\text { number of } \\
\text { local } \\
\text { expense } \\
\text { control } \\
\text { meters }\end{array}$ & $\begin{array}{c}\text { Number of } \\
\text { successful } \\
\text { electricity } \\
\text { price } \\
\text { issuing }\end{array}$ & $\begin{array}{c}\text { Number of } \\
\text { failed } \\
\text { electricity } \\
\text { price issuing }\end{array}$ & $\begin{array}{c}\text { Success rate } \\
\text { for electricity } \\
\text { price issuing }\end{array}$ \\
\hline CZMBL public substation & 99 & 99 & 0 & $100.00 \%$ \\
\hline WM bureau management & 226 & 225 & 1 & $99.56 \%$ \\
\hline $\begin{array}{l}\text { LJWY company's special substation } \\
\text { comblation }\end{array}$ & 326 & 212 & 1 & $99.53 \%$ \\
\hline 445 public substation & 282 & 281 & 0 & $99.39 \%$ \\
\hline HRX real estate company & & 1 & $99.65 \%$ \\
\hline
\end{tabular}

Table 4 Partial test results for electricity price issuing under the first transparent task mode

The average success rate for electricity price issuing of the current local expense control meter is up to $99.18 \%$ or even $100 \%$ in certain transformer districts. The experiment results satisfy the theoretical analysis in this paper, and the success rate of site electric price issuing is equivalent to the rate of the meter reading.

\section{Conclusions}

Electricity price issuing for a local intelligent electric energy meter under the transparent task mode avoids the requirements of a traditional electricity issuing mode for a high real-time message channel. However, the simulation transformer district and site transformer district tests demonstrate that this method increases the success rate of electricity price issuing. The transparent task mode improves the compatibility of the collection system for the terminals of different manufacturers, eliminates the influences of different devices and overtime settings on tasks, and solves the frequent updating problems caused by incompatibility. In addition, new hardware is not necessary for this method, which only requires updating the concentrator and the software system of the primary station at a relatively small cost for reconstruction. Table 5 presents the technical advantages of the transparent task. 


\begin{tabular}{|l|l|l|}
\hline & \multicolumn{1}{|c|}{$\begin{array}{c}\text { Transparent transmission } \\
\text { method }\end{array}$} & \multicolumn{1}{|c|}{ Transparent task method } \\
\hline Time analysis & $\begin{array}{l}\text { The electricity price issuing } \\
\text { for 70\% of electric meters can } \\
\text { be completed within thre } \\
\text { months. Site price change is } \\
\text { required for the remaining } \\
\begin{array}{l}30 \% \text { of electric energy meters } \\
\text { about 2 million). }\end{array}\end{array}$ & $\begin{array}{l}\text { The electricity price parameter } \\
\text { issuing for 6.78 million electric } \\
\text { energy meters in Xinjiang } \\
\text { Company can be completed } \\
\text { within 5-10 days in a theoretical } \\
\text { demonstration. }\end{array}$ \\
\hline Cost analysis & $\begin{array}{l}\text { Labor, vehicle, and equipment } \\
\text { costs are estimated at RMB 40 } \\
\text { million in each price } \\
\text { adjustment. }\end{array}$ & $\begin{array}{l}\text { About RMB 5 million is the } \\
\text { required investment for the } \\
\text { software update of the } \\
\text { concentrator and manufacturer } \\
\text { development to satisfy multiple } \\
\text { demands for electricity price } \\
\text { issuing. }\end{array}$ \\
\hline $\begin{array}{l}\text { Safety risk } \\
\text { analysis }\end{array}$ & $\begin{array}{l}\text { The great number of workers } \\
\text { who execute electricity price } \\
\text { issuing on site is at risk for } \\
\text { personal safety. }\end{array}$ & $\begin{array}{l}\text { Workers are not at risk for } \\
\text { personal safety in case of remote } \\
\text { implementation. }\end{array}$ \\
\hline $\begin{array}{l}\text { Superior } \\
\text { service and } \\
\text { public } \\
\text { sentiment risk } \\
\text { analysis }\end{array}$ & $\begin{array}{l}\text { Due to long period and low } \\
\text { accuracy rate and success rate, } \\
\text { the price adjustment demands } \\
\text { of government and the public } \\
\text { cannot be satisfied, with } \\
\text { large-scale complaint risk. }\end{array}$ & $\begin{array}{l}\text { The complaint risk is low because } \\
\text { of the short implementation } \\
\text { period, high accuracy rate and } \\
\text { success rate, and rapid response to } \\
\text { the demands of the government } \\
\text { and the public. }\end{array}$ \\
\hline
\end{tabular}

Table.5 Conclusions on the technical advantages of transparent task

An electric power company can expand to other businesses more conveniently by using an electricity price-issuing model with a high success rate. For example, clock modification and the remaining amount adjustment for the electric energy meter can be executed by the transparent task to provide more possibilities for developing an intelligent electric grid.

\section{References}

[1] SGCC 12th Five Year Plan for Electricity Marketing and Development;

[2] Proposals about accelerating construction for electricity utilization information collection system, SGCC Marketing [2010] No. 119;

[3] Wang Ning, Zhang Qiang, Electric price management for local intelligent electric energy meter, Chinese Market, 2015(28):147-148;

[4] Han Dong, Modeling design for data caching in interface transparent transmission, Electronic Engineering Design, 2014, 22(20);

[5] Li Chong, Tang Ruyi, Geng Jianpo, Ma Hongming, Wang Junlong, Shi Wei, Research on remote sending technology for tiered pricing for electric parameters of intelligent electric energy meter, Hebei Electronic Power, 2012(5):7-9;

[6] Jin Fubao, Cao Jun, Design of remote meter reading system based on GPRS network, Electrical Measurement \& Instrumentation, 2006, 43(10):38-41;

[7] Communication agreement of electric information collection system for Q/GDW1376.1-2013 power consumers: communication agreement for primary station and collection terminal, SGCC Corporate Standards, 2013. 